\title{
Aplikasi Pembelajaran Algoritma Affine Cipher Dan Vigenere Cipher Menggunakan Metode Computer Assisted Instruction
}

\author{
Eveline Togiana \\ STMIK Budi Darma Medan, JI. SM.Raja No.338 Sp.Limun Medan, Sumut, Indonesia. \\ http://www.stmik-budidarma.ac.id // Email : evelinetogiana@gmail.com
}

\begin{abstract}
Learning is a process of communication between teachers and students. Cryptographic learning is very important for computer students to know the ways to secure data. Then learning is needed about data security, namely using cryptographic methods with the Affine Cipher algorithm and vigenere cipher. The Affine Cipher algorithm is a form of classical cryptography that uses the nature of substitution in the process of encoding data where the process is done by multiplying each plaintext value by a value and adding it with a shift. Vigenere Cipher algorithm is one form of classical cryptography with substitution techniques. Computer Assisted Instruction (CAI) is a computer for presenting learning material that aims to make students more active in learning material in the use of computer media. In its development Computer Assisted Instruction (CAl) has five learning system models namely tutorial models, practice models and exercises, problem solving models, simulation models, and game models, the advantages of Computer Assisted Instruction (CAl) in education can increase student motivation in learning, improve student understanding in the material presented.
\end{abstract}

\section{Kata Kunci: Pembelajaran, Algoritma Affine dan Vigenere Cipher, Computer Assisted Instruction (CAI).}

\section{PENDAHULUAN}

Pembelajaran merupakan proses komunikasi antara guru dan peserta didik, proses pembelajaran yang ada saat ini masih cenderung menggunakan manualisasi, pendidik hanya menulis kemudian peserta didik hanya mencatat dan menghapalnya. Tentu hal ini akan menimbulkan rasa kebosanan dalam mengikuti proses belajar mengajar, sehingga peserta didik kurang memahami dan penguasaan materi kurang maksimal dan juga akan mengurangi kemauan belajar peserta didik, untuk itu perlu disiapkan suatu media yang dapat menyampaikan materi pembelajaran yang dapat menarik perhatian peserta didik untuk mempelajarin materi tersebut.

Kriptografi sangat penting untuk dipelajari bagi mahasiswa komputer, agar mengetahui cara-cara mengamankan data/teks [11]. Oleh karena itu ilmu untuk mengamankan data/teks harus semakin ditingkatkan. Secara etimologi Kriptografi (cryptography) berasal dari Bahasa Yunani, yang terdiri dari dua suku kata yaitu "cryptos" artinya "secref" (rahasia), sedangkan "graphein" artinya "writing" (tulisan), Jadi, kriptografi berarti "secret writing" (tulisan rahasia) [8]. Awal mula kriptografi dipahami sebagai ilmu tentang menyembunyikan pesan, tetapi seiring perkembangan zaman hingga saat ini pengertian kriptografi berkembang menjadi ilmu tentang teknik matematis yang digunakan untuk menyelesaikan persoalan keamanan berupa privasi dan otentikasi.

Algoritma adalah urutan langkah-langkah untuk memecahkan suatu masalah. Metode menyembunyikan pesannya adalah dengan teknik substitusi atau transposisi atau keduanya. Teknik substitusi adalah menggantikan karakter dalam plaintext menjadi karakter lain yang hasilnya adalah ciphertext, sedangkan transposisi adalah teknik mengubah plaintext menjadi ciphertext dengan cara permutasi karakter [9]. Algoritma affine cipher merupakan salah satu bentuk kriptografi klasik yang menggunakan sifat subtitusi dalam peroses penyandian datanya dimana prosesnya dilakukan dengan mengalikan masing-masing nilai plaintext dengan sebuah nilai dan menambahkannya dengan sebuah pergeseran. Algoritma vigenere cipher merupakan salah satu bentuk kriptografi klasik dengan teknik substitusi.

Pembelajaran mulai dikemas secara lebih praktis dan menarik melalui media komputer karena komputer mampu menampilkan teks, warna, suara, video, gerak, gambar serta mampu menampilkan kepintaran yang dapat menyajikan proses interaktif. Berbagai jenis aplikasi teknologi komputer dalam pendidikan umumnya dikenal dengan istilah Computer assisted intruction (CAl). Model pembelajaran 
yang diterapkan dalam pembelajaran berbantuan komputer secara umum dapat diklasifikasikan menjadi empat model, yaitu tutorial, drill and practice, problem-solving, simulation dan games.

\section{LANDASAN TEORI}

\subsection{Computer Assisted Instruction (CAI)}

Menurut Herman Dwi Surjono istilah CAI (Computer-Assisted Instruction) umumnya menunjuk pada semua software pendidikan yang diakses melalui komputer dimana anak didik dapat berinteraksi dengannya. Menurut Azhar Arsyad dalam bukunya mengatakan bahwa Pembelajaran berbasis komputer merupakan program pembelajaran yang digunakan dalam proses pembelajaran dengan perangkat lunak berupa program komputer yang berisi materi pelajaran.

Dalton dan Hannafin melakukan penelitian yang melibatkan siswa SMU dan hasil penelitian menunjukkan bahwa CAI merupakan sistem penyampaian instruksional yang paling efektif dibandingkan dengan video maupun video interaktif.

\subsection{Tipe-Tipe Computer Assisted Instruction (CAI)}

Menurut para ahli (James Lockard, Peter D. Abrams and Weslwy A. Many mengklasifikasikan tipe program CAI menjadi lima tipe, yakni: Tutorials, Drill and Practice, Problem Solving, Simulations dan Games Instructional. Adapun pengertian dari tipe-tipe pembelajaran CAI, diantaranya:

\section{Tutorials}

Merupakan suatu program yang dirancang untuk bertindak sebagai tutor atau guru. CAI tutorial menyajikan informasi atau konsep baru melalui monitor, dan siswa diberi kesempatan untuk berinteraksi dengan informasi atau konsep baru tersebut. Komputer berperan layaknya sebagai seorang guru. Siswa harus bisa berpartisipasi aktif dalam proses belajarnya dengan berinteraksi dengan komputer. Materi pelajaran dalam satu sub pokok bahasan disajikan lebih dulu kemudian diberikan soal latihan. CAI tutorial juga memberikan alternatif percabangan sub pokok bahasan, sesuai dengan kebutuhan belajar siswa dan persyaratan sub pokok bahasan tersebut.

2. Drill and Practice

Drill and Practice menyajikan materi pelajaran untuk dipelajari secara berulang. Tipe program ini cocok dipergunakan sewaktu pengajar menyajikan latihan soal dengan disertai umpan balik. Selama pelaksanaan latihan-latihan soal pada Drill and Practice, komputer dapat menyimpan jawaban yang salah, laporan nilai, contoh jawaban yang salah dan pengulangan lewat contoh-contoh masalah yang telah dijawab secara tidak benar.

3. Problem Solving

Menyajikan situasi (masalah) pada komputer yang diselesaikan melalui suatu proses deduksi logika, sintesis dan implementasi. CAI problem solving, seperti halnya CAI simulasi, yang dikembangkan dengan melibatkan komputer digunakan untuk meningkatkan proses mengajar dan meningkatkan strategi pemecahan masalah tingkat tinggi.

\section{Simulations}

Merupakan suatu presentasi atau model dari suatu kejadian nyata atau imajinasi dari suatu obyek, sistem atau beberapa kejadian. Program CAI simulasi masih mengandung elemen-elemen pokok dari sesuatu yang disimulasikan. Program CAI dengan model simulasi memungkinkan siswa memanipulasikan tanpa harus menanggung resiko yang tidak menyenangkan. Siswa seolah-olah terlibat dan mengalami kejadian sesungguhnya dan umpan balik diberikan sebagai akibat dari keputusan yang diberikannya.

5. Games Instructional

Memiliki kelebihan yaitu mampu mendorong motivasi tinggi siswa. Terkadang ada mata pelajaran yang kurang menarik minat dan motivasi siswa, maka guru dapat menggunakan program CAl games instructional yang terintegrasi dan terseleksi secara baik. Program CAI instructional games dapat memberikan penguatan dalam mengajar keterampilan, konsep dan informasi. CAl permainan menawarkan kepada siswa kemungkinan yang sangat menarik, tetapi hal itu harus terkait dengan tujuan utama dan yang terpenting dalam mengembangkan dan memberi penguatan yaitu menyaring beberapa aspek proses belajar. CAI permainan harus tetap menggunakan nilai-nilai pendidikan sebagai tujuan utamanya.

\subsection{Kelebihan Computer Assisted Instruction (CAI)}

Menurut Wena, menyebutkan beberapa kelebihan maupun keuntungan yang akan diperoleh dengan pembelajaran berbantuan komputer yaitu: 
1. Memberi kesempatan kepada siswa untuk memecahkan masalah secara individual.

2. Menyediakan presentasi yang menarik dengan animasi.

3. Menyediakan pilihan isi pembelajaran yang banyak dan beragam.

4. Mampu membangkitkan motivasi siswa dalam belajar.

5. Mampu mengaktifkan dan menstimulasi metode mengajar dengan baik.

6. Meningkatkan pengembangan pemahaman siswa terhadap materi yang disajikan.

7. Merangsang siswa belajar dengan penuh semangat, materi yang disajikan mudah dipahami oleh siswa.

8. Siswa mendapat pengalaman yang bersifat konkret, retensi siswa meningkat.

9. Memberi umpan balik secara langsung.

\subsection{Kelemahan Computer Assisted Instruction (CAI)}

Menurut Wena, mengemukakan beberapa kelemahan pembelajaran dengan bantuan komputer yaitu:

1. Hanya efektif jika digunakan satu orang atau kelompok kecil. Kelemahan ini sudah diatasi karena saat ini pengadaan komputer sangat mudah.

2. Jika tampilan fisik isi pembelajaran tidak dirancang dengan baik atau hanya merupakan tampilan seperti pada buku teks biasa, pembelajaran melalui media komputer tidak akan mampu meningkatkan motivasi belajar siswa (siswa cepat bosan).

3. Guru yang tidak memahami aplikasi program komputer tidak dapat merancang pembelajaran lewat media komputer, guru harus bekerja sama dengan ahli program komputer grafis, juru kamera dan teknisi komputer.

\subsection{Kriptografi}

Kriptografi (cryptography) berasal dari Bahasa Yunani, terdiri dari dua suku kata yaitu "cryptos" artinya "secret" (rahasia), sedangkan "graphein" artinya "writing" (tulisan), Jadi, kriptografi berarti "secret writing" (tulisan rahasia). Kriptografi adalah ilmu yang mempelajari teknik-teknik matematika yang berhubungan dengan aspek keamanan informasi, seperti kerahasiaan, keadsahan data, integritas data, serta autentikasi data (Menezes, Oorschot and Vanstone, 1996) [9]. Secara umum kriptografi adalah ilmu dan seni untuk menjaga kerahasiaan berita (bruce Schneier - Applied Criptography).
Ada empat tujuan mendasar dari ilmu kriptografi ini yang juga merupakan aspek keamanan informasi yaitu [14]:

1. Kerahasiaan, adalah layanan yang ditujukan untuk menjaga agar pesan tidak dapat dibaca oleh pihak-pihak yang tidak berhak

2. Integritas data, adalah layanan yang menjamin pesan masih asli/utuh atau belum pernah dimanipulasi selama pengiriman

3. Otentikasi, adalah layanan yang berhubungan dengan identifikasi, baik mengidentifikassi kebenaran pihak-pihak yang berkomunikassi (user authentication atau entity authentication) maupun mengidentifikasi kebenaran sumber pesan (origin authentication)

4. Nirpenyangkalan (non-repudiation), adalah layanan untuk mencegah entitas yang berkomunikasi melakukan penyangkalan, yaitu pengirim pesan menyangkal melakukan pengiriman atau penerima pesan menyangkal telah menerima pesan.

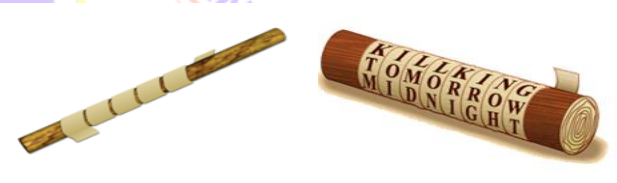

\section{Gambar 1 (a) Sebuah Scytale; (b) Pesan ditulis secara horizontal}

(Sumber: Rinaldi Munir, 2006: 10)

Proses penyandikan plainteks menjadi cipherteks disebut Enkripsi (encryption) atau enciphering (standard nama menurut ISO 7498-2), sedangkan proses mengembalikan cipherteks menjadi plainteks semula dinamakan Dekripsi (decryption) atau deciphering (standard nama menurut ISO 7498-2). Enkripsi dan Dekripsi dapat diterapkan baik pada pesan yang dikirim maupun pada pesan tersimpan. Istilah encryption of data in motion mengacu pada enkripsi pesan yang ditransmisikan melalui saluran komunikasi, sedangkan istilah encryption of data at-rest mengacu pada enkripsi dokumen yang disimpan didalam strorage. Contoh encryption of data in motion adalah pengiriman nomor PIN dari mesin ATM ke computer server di kantor bank pusat.(Rinaldi Munir, 2006: 4)

\subsection{Algoritma Affine Cipher}

Affine cipher adalah perluasan dari caesar cipher, yang mengalikan plainteks dengan sebuah nilai dan menambahkannya dengan 
sebuah pengeseran. Secara matematis enkripsi plainteks $(P)$ menghasilakan Cipherteks (C) dinyatakan dengan fungsi kongruen :

$C \equiv m P+b(\bmod n)(1)$

Yang dalam hal ini $\mathrm{n}$ adalah ukuran alphabet, $m$ adalah bilangan bulat yang harus relatif prima dengan $n$ (jika tidak relatif prima, maka dekripsi tidak bisa dilakukan) dan $b$ adalah jumlah pergeseran. Untuk melakukan dekripsi, persamaan (1) harus dipecahkan untuk memperoleh $P$. Solusi kekongruenan tersebut hanya ada jika invers $m(\bmod n)$, dinyatakan dengan $m^{-1}$, Jika $m^{-1}$ ada maka dekripsi dapat dilakukan dengan persamaan sebagai berikut :

$$
P \equiv m^{-1}(C-b)(\bmod n)(2)
$$

Keterangan :

$C \quad=$ Chipertext

$m P=$ Adalah bilangan bulat yang harus relatif prima dengan $n$

$$
\begin{array}{ll}
P & =\text { Plaintext } \\
m^{1} & =\text { Invers } \mathrm{m} \\
b & =\text { Jumlah pergeseran } \\
n & =\text { Adalah ukuran alphabet }
\end{array}
$$

Affine cipher bukanlah cipher yang aman sebab kuncinya ( $m$ dan $b$ ) dapat ditemukan dengan exhaustive key search. Karena menggunakan alfabet yang hanya 26 huruf, maka hanya ada 25 pilihan untuk nilai $b$ dan hanya ada 12 buah nilai $m$ yang relatif prima dengan 26 yaitu : $(1,3,5,7,9,15,17,19,21$, 23, dan 25). Dengan mencoba semua kombinasi $m$ dan $b$, maka nilai $m$ dan $b$ yang cocok dapat ditemukan dengan mudah. Salah satu cara memperbesar faktor kerja untuk exhaustive key search, enkripsi sebaiknya tidak dilakukan terhadap huruf individual, tetapi dalam blok-blok huruf.(Rinaldi Munir, 2006: 77)

\subsection{Algoritma Vigenere Cipher}

Vigenere cipher adalah contoh terbaik dari cipher alfabet-majemuk "manual". Algoritma ini dipublikasikan oleh diplomat (sekaligus seorang kriptologis) Perancis, Blaise de Vigenere pada abad 16, meskipun Giovan Bastista Belaso telah menggambarkannya pertama kali pada tahun 1553 seperti ditulis didalam bukunya "La Cifra del Sig". Vigenere Cipher dipublikasikan pada tahun 1586, tetapi algoritma tersebut baru dikenal luas 200 tahun kemudian yang oleh penemunya cipher tersebut kemudian dinamakan Vigenere Cipher. Cipher ini berhasil dipecahkan oleh Babbage dan Kasiski pada pertengahan Abad 19. Vigenere cipher digunakan oleh Tentara Konfiderasi (Confederate Army) pada Perang Sipil Amerika (America Civil war). Vigenere cipher sangat dikenal karena mudah dipahami dan diimplementasikan. Cipher menggunakan bujursangkar vigenere untuk melakukan enkripsi.

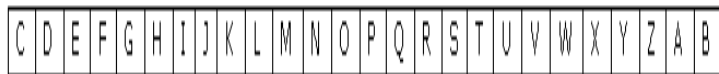

Kolom paling kiri dari bujursangkar menyatakan huruf-huruf kunci, sedangkan baris paling atas menyatakan huruf-huruf cipherteks yang diperoleh dengan caesar cipher, yang mana jumlah pengeseran huruf plainteks ditentukan nilai numerik huruf kunci tersebut (yaitu, $a=0, b=1, c=2, \ldots, z=25$ ). (Rinaldi Munir, 2006: 79)

Bujursangkar vigenere digunakan untuk memperoleh cipherteks dengan menggunakan kunci yang sudah ditentukan. Jika panjang kunci lebih pendek daripada panjang plainteks, maka kunci diulang penggunaanya (sistem periodik). Bila panjang kunci adalah $m$, maka periodenya dikatakan $m$. Setiap huruf plainteks akan dienkripsi dengan setiap huruf kunci dibawahnya. (Rinaldi Munir, 2006: 80)

Secara matematis, misalkan kunci dengan panjang $m$ adalah rangkaian $k_{1} k_{1} \ldots$ $k_{m}$, plainteks adalah rangkaian $p_{1} p_{1} \ldots p_{1}$, dan cipherteks adalah rangkaian $c_{1} c_{1} \ldots c_{1}$, maka enkripsi pada vigenere cipher dapat dinyatakan sebagai:

$$
\begin{gathered}
c_{1}=\left(p_{i}+k_{r}\right) \bmod 26 \\
(1 \leq i \leq t)
\end{gathered}
$$

dan

$i=r(\bmod m)$ $\leq t)$

Dekripsi pada vigenere cipher dilakukan dengan cara yang berkebalikan, yaitu menarik garis mendatar dari huruf kunci sampai kehuruf cipherteks yang dituju, lalu dari huruf cipherteks tarik garis vertikal keatas sampai kehuruf plainteks. Secara matematis dekripsi dinyatakan dengan persamaan: $p_{i}=\left(c_{i}+k_{r}\right)$ $\bmod 26$

\section{HASIL DAN PEMBAHASAN}

\subsection{Analisa Penyajian Materi Pembelajaran Algoritma Affine dan Vigenere Cipher}

Alasan utama aplikasi pembelajaran Algoritma Affin dan Vigenere Cipher menggunakan metode CAI (Computer Assisted Instructions) ini adalah untuk mendorong perkembangan kemampuan penyelesaian masalah para peserta didik khususnya dalam memecahkan masalah enkripsi dan dekripsi Algoritma Affin dan Vigenere Cipher, mendorong kemauan peserta didik dalam belajar semakin meningkat dengan adanya bentuk tampilan slide yang menarik, sehingga menggurangi rasa kebosanan pada peserta didik. Pembelajaran metode CAI dapat menghemat 
waktu dalam proses belajar mengajar dan menarik melalui media komputer karena komputer mampu menampilkan teks, warna, suara, video, gerak, gambar serta dapat menyajikan proses interaktif dan Diharapkan kemampuan penyelesaian masalah para peserta didik akan semakin tajam. Tujuan yang lain adalah untuk memajukan pemikiran kritis para peserta didik dan proses belajar mengajar interaktif, menarik dan mampu membangkitkan motivasi peserta didik dalam belajar.

\subsection{Penerapan Metode Computer Assisted Instruction}

Computer Assisted Instructions (CAl) adalah penggunaan komputer secara langsung terhadap peserta didik untuk menyampaikan isi pelajaran, memberikan latihan-latihan dan menguji kemampuan belajar peserta didik. Adapun beberapa model dari Metode Pembelajaran CAI (Computer Assisted Instructions) antara lain Tutorials, Drill and Practice, Problem Solving, Simulations dan Games. Berikut ini merupakan langkah dalam pembelajaran berbasis komputer:

\section{Model Tutorials}

Tutorial didefenisikan sebagai bentuk pembelajaran khusus dengan pembimbing yang terkualifikasi, penggunaan komputer untuk tutorial pembelajaran. Tutorial dengan metode alternatif diantaranya bacaan, demonstrasim penemuan bacaan atau pengalaman yang membutuhkan respon secara verbal dan tulisan serta adanya ujian. Program tutorial pada dasarnya sama dengan program bimbinga, yang bertujuan memberikan bantuan kepada siswa agar dapat mencapai hasil belajar secara optimal.

\section{Model Drill and Practice}

Model Drill and Practice adalah suatu model dalam pembelajaran dengan jalan melatih siswa terhadap bahan pelajaran yang sudah diberikan. Dengan adanya latihan yang terus menerus, maka akan tertanam dan kemudian akan menjadi kebiasaan.

Berikut beberapa penyajian Model Drill and Practice, yaitu:

1. Penyajian masalah-masalah dalam bentuk latihan soal pada tingkat tertentu dari kemampuan siswa.

2. Siswa mengerjakan soal-soal latihan

3. Jika jawaban yang diberikan siswa benar program menyajikan materi selanjutnya dan jika jawaban siswa salah, program menyediakan fasilitas untuk mengulang latihan yang dapat diberikan secara parsial atau pada akhir keseluruhan soal.

3. Simulasi

Model simulasi pada dasarnya merupakan salah sau strategi pembelajaran yang bertujuan memberikan pengalaman belajar yang lebih kongkrit melalui penciptaan tiruantiruan bentuk pengalaman yang mendekati suasana sebenernya dan berlangsung dalam suasan yang tanpa resiko. Menurut Sridadi, simulasi adalah program komputer yang berfungsi untuk menirukan perilaku sistem nyata tertentu. Tujuan simulasi antara lain untuk pelatihan, studi prilaku sistem dan hiburan/permainan.

\section{Permainan (games)}

Model permainan merupakan salah satu bentuk model yang didesain untuk membangkitkan kegembiraan pada siswa sehingga dapat meningkatkan kemungkinan tersimpannya lebih lama konsep, pengetahuan ataupun keterampilan yang diharapkan dapat mereka peroleh permainan tersebut. Tujuan dari model permainan adalah untuk menyediakan suasana (lingkungan) yang memberikan fasilitas belajar yang menambah kemampuan siswa. Model permaian tidak perlu menirukan realita namun dapat memiliki karakter yang menyediakan tantangan yang menyenangkan bagi siswa

Pada tahap ini dilakukan penerapan hasil perancangan antarmuka ke dalam sistem yang dibangun dengan menggunakan perangkat lunak yang telah dipaparkan pada sub bab implementasi perangkat lunak, yang tercantum pada gambar dibawah ini dan untuk antarmuka selanjutnya dapat dilihat pada lampiran berikut ini :

\section{Tampilan Menu Utama}

Halaman utama merupakan halaman pembuka dari aplikasi yang dirancang

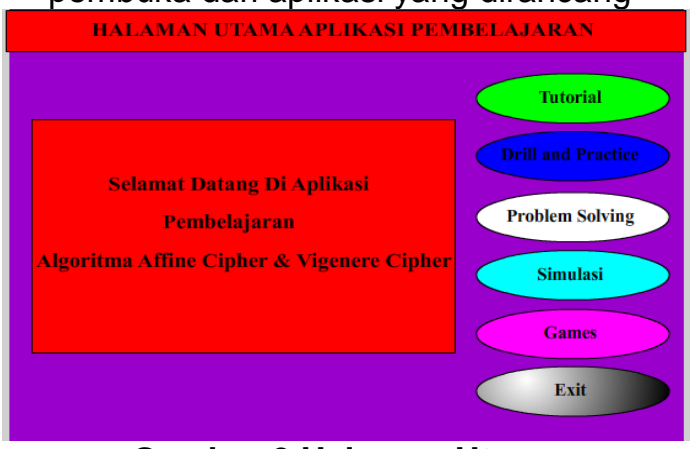

Gambar 2 Halaman Utama

\section{Tampilan Menu Tutorial}


Pada tampilan menu Tutorial algoritma Affine dan Vigenere Cipher terdapat menu pilihan. Adapun tampilan menunya sebagai berikut:

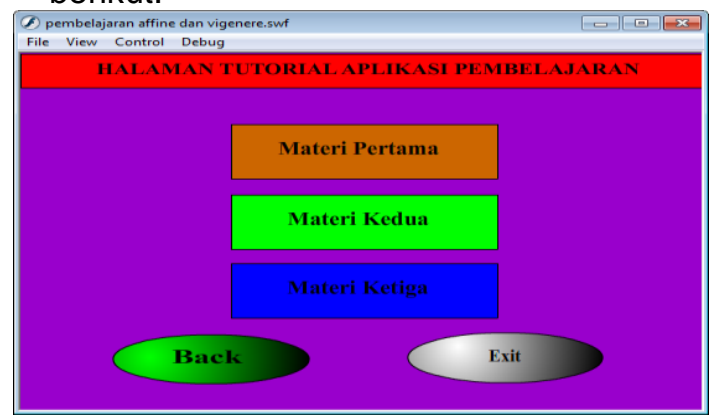

Gambar 3 Tampilan Halaman Tutorial

\section{Tampilan Menu Drill and Practice}

Pada tampilan menu Drill and Practice pembelajaran algoritma Affine dan Vigenere Cipher terdapat menu pilihan. Adapun tampilan menunya sebagai berikut:

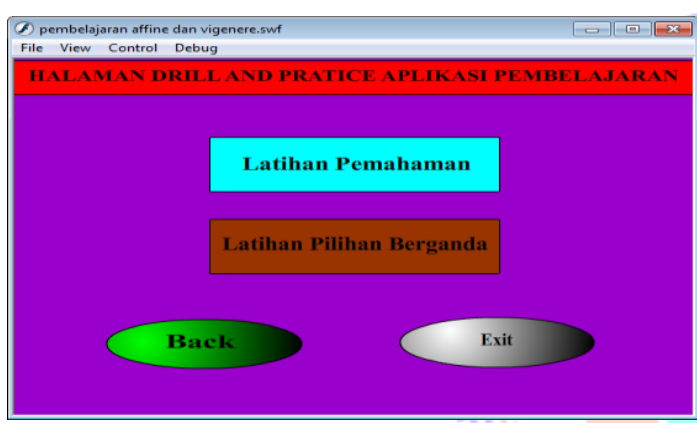

Gambar 4 Tampilan Halaman Drill and Practice

4. Tampilan Menu Simulasi

Pada tampilan menu Simulasi pembelajaran menampilkan video proses enkripsi dan dekripsi dari algoritma Affine dan Vigenere Cipher. Adapun tampilannya sebagai berikut:

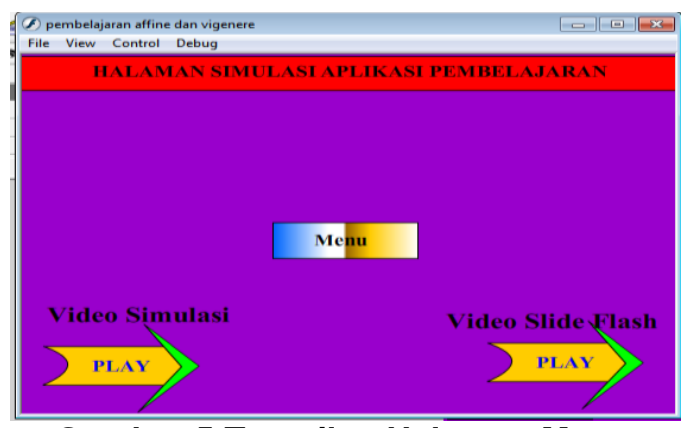

Gambar 5 Tampilan Halaman Menu Simulasi

\section{Tampilan Menu Games}

Pada tampilan menu Games berisikan permainan teka-teki silang. Adapun tampilannya sebagai berikut:

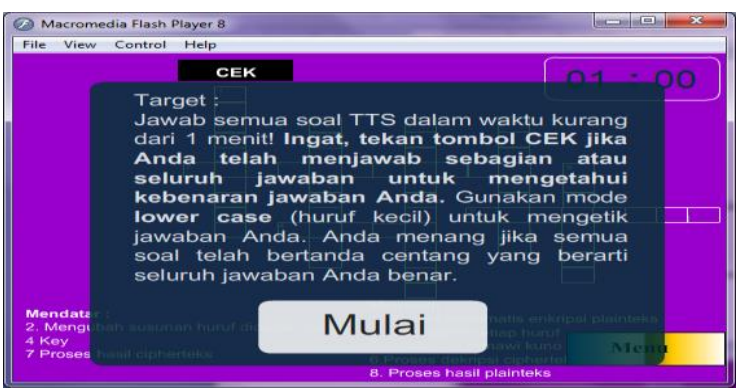

\section{Gambar 6 Tampilan Halaman Menu Games}

\section{KESIMPULAN}

Setelah menyelesaikan perancangan aplikasi pembelajaran algoritma Affine Cipher dan Vigenere Cipher ini, maka penulis dapat menarik kesimpulan sebagai berikut:

1. Penyajian Aplikasi pembelajaran algoritma Affine Cipher dan Vigenere Cipher dilakukan melalui media komputer agar proses belajar dan mengajar lebih interaktif, menarik dan mampu membangkitkan motivasi belajar pada peserta didik.

2. Dari penelitian yang telah dilakukan bahwa dengan menerapkan metode Computer Assisted Instruction (CAI) pada proses pembelajaran algoritma Affine Cipher dan Vigenere Cipher ini, dapat mempermudah mahasiswa dalam proses belajar mengajar dan memberikan layanan informasi dalam memahami suatu materi pembelajaran.

3. Aplikasi pembelajaran algoritma Affine Cipher dan Vigenere Cipher yang dirancang menggunakan software Macromedia Flash 8.

\section{DAFTAR PUSTAKA}

[1]. Adi Nugroho, "Rekayasa Perangkat Lunak Berorientasi Objek Dengan Metode USDP", Penerbit Andi, Edisi 1, 2010

[2]. Ahmad Saifudin, "Pengembangan Media Pembelajaran Berbasis Komputer Mata Pelajaran IPS SMP", Vol. I, No. 2, 2001

[3]. Eka Nella Kresma, "Perbandingan Pembelajaran Konvesional Dan Pembelajaran Berbasis Masalah Terhadap Titik Jenuh Siswa Maupun Hasil Belajar Siswa Dalam Pembelajaran Matematika", Vol. I, 2014

[4]. Iwayan Dikse \& I Putu Sundika, "Animasi Dengan Flash 8", Penerbit Graha IImu, Yogyakarta, 2011

[5]. Mardi Iwan Gunawan Saragih, "Perancangan Aplikasi Pembelajaran Bangun Ruang Pada Tingkat SD Berbasis Flash Dengan Metode 
Computer Assisted Intruction", Vol. VII, No. 2, 2014

[6]. Martinis Yamin, "Strategi \& Metode Dalam Model Pembelajaran", Penerbit GP Press Group, Jakarta, Edisi 1, 2013

[7]. Muhammad Fadlan, "Perancangan Aplikasi Pembelajaran Sejarah Nabi Muhammad Saw Berbasis Multimedia Dengan Metode Computer Based Instruction (CBI)", Vol. IV, No. 3, 2014

[8]. Rahmiah, "Implementasi Penyembunyian Dan Penyandian Pesan Pada Citra Menggunakan Algoritma Affine Cipher Dan Metode Least Significant Bit", Vol. VI, No. 1, 2014

[9]. Rinaldi Munir, "Kriptografi", Penerbit Informatika Bandung, Bandung, Edisi 1, 2006

[10]. Rinaldi Munir, "Algoritma \& Pemrograman Dalam Bahasa Pascal Dan C", Penerbit Informatika Bandung, Bandung, Edisi 3, 2011

[11]. Septiana Firdaus, "Perancangan Aplikasi Multimedia Interaktif Company Profile Generic", Vol. 01, No. 09, 2012

[12]. Tonni Limbong, Parasian DP Silitonga, Testing the Classic Caesar Cipher Cryptography using of Matlab, 2017, International Journal Of Engineering Research \& Technology, Vol 6, Issue 2 p. $175-178$

[13]. Widi Hardiyanto, "Pemanfaatan Media Pembelajaran Fisika Berbasis Macromedia Flash 8 Guna Meningkatkan Motivasi Belajar Siswa Pada Pokok Bahasan Sifat Mekanik Bahan Kelas X TKJ 2 SMK Batik Perbaik Tahun Pelajaran 2011/2012", Vol. 01, No. 1, 2012

[14]. Lamhot Sitorus, 2015. Algoritma Dan Pemrograman, Andi Offset, Yogyakarta. 